\title{
Mercúrio no meio ambiente: uma revisão sobre seus efeitos toxicológicos e as principais fontes de emissão
}

\section{Mercury in the environment: a review on its toxicological effects and the main sources of emission}

Data de entrada: 05/12/2019

Data de aprovação: 20/12/2019

Wedlas Júnior Pereira Brito ${ }^{1 * *}$ | Bruno Silva de Holanda ${ }^{1}$ | Fernanda da Silva de Andrade Moreira ${ }^{1}$ | Jéssica Cristina Conte da Silva ${ }^{1}$ | Antonio Rodrigues Fernandes ${ }^{2}$

ORCID ID

Brito WJP (D) https://orcid.org/0000-0001-8490-7184

Holanda BS (D) https://orcid.org/0000-0002-6599-3723

\author{
Moreira FSA (D) https://orcid.org/0000-0002-7426-1604 \\ Silva JCC (D) https://orcid.org/0000-0001-7686-572X \\ Fernandes AR (D) https://orcid.org/0000-0001-6270-3930
}

\section{Resumo}

Esta revisão descreve o comportamento do mercúrio $(\mathrm{Hg})$ no ambiente, desde sua origem até as implicações no ecossistema e na saúde humana. $\mathrm{O} \mathrm{Hg}$ constitui um dos poluentes de maior risco para o equilíbrio ecológico e saúde humana, justificado pela elevada toxicidade e potencial de bioacumulação e biomagnificação através da cadeia alimentar. Nos solos a mobilidade do $\mathrm{Hg}$ é controlada pelas espécies do elemento e pelos atributos do solo, como $\mathrm{pH}$, matéria orgânica e mineral de argila. Em plantas, o Hg afeta a fotossíntese, a absorção de nutrientes e a transpiração, porém algumas plantas desenvolveram mecanismos para tolerar esse metal, como acumular altas concentrações nas raízes sem translocá-lo para as partes aéreas. Foram abordadas as principais fontes de $\mathrm{Hg}$, os métodos de determinação usados para quantificar esse metal e a ocorrência em ecossistemas e seus desdobramentos, bem como foram identificadas áreas com elevadas contaminações por diferentes fontes, com destaque para contaminação industrial e mineração. Dessa forma, mais estudos devem ser replicados, no intuito de garantir saltos para promover a redução da emissão e incorporação ao sistema, assim como recuperar as áreas já contaminadas.

Palavras-chave: Mercúrio. Saúde Humana. Meio Ambiente.

\section{Abstract}

This review describes the behavior of mercury $(\mathrm{Hg})$ in the environment, from its origin to the implications on the ecosystem and human health. $\mathrm{Hg}$ is one of the pollutants at greatest risk for ecological balance and human health, justified by the high toxicity and potential for bioaccumulation and biomagnification through the food chain. In soils the mobility of $\mathrm{Hg}$ is controlled by the element species and soil attributes, such as $\mathrm{pH}$, organic matter and clay mineral. In plants $\mathrm{Hg}$ affects photosynthesis, nutrient absorption and transpiration, but some plants have developed mechanisms to tolerate this metal, such as accumulating high concentrations in the roots without translocating it to the aerial parts. The main sources of $\mathrm{Hg}$, the methods of determination used to quantify this metal and its occurrence in ecosystems and their consequences, as well as areas with high contamination by different sources were identified, especially industrial contamination and mining. Thus, more studies must be replicated, in order to guarantee jumps to promote emission reduction and incorporation into the system, as well as to recover already contaminated areas.

Keywords: Mercury. Human Health. Environment.

\footnotetext{
${ }^{1}$ Universidade Federal do Pará - Belém - Pará - Brasil.

2 Universidade Federal Rural da Amazônia (UFRA) - Belém - Pará - Brasil.

* Autor correspondente: juniorbrito90agmail.com.
} 


\section{INTRODUÇÃO}

O mercúrio pode ser liberado para o ar ou outros meios quando esses materiais são queimados, processados ou eliminados, além disso ele está presente em diversas matérias-primas, como carvão, petróleo, madeira e jazidas de minerais diversos. Desde o surgimento dos seres humanos, e mais fortemente a partir da Revolução Industrial, fontes antrópicas têm tido uma contribuição significativa para a distribuição do mercúrio e seus compostos no meio ambiente (WHO, 2003).

O mercúrio $(\mathrm{Hg})$ é um metal naturalmente encontrado na crosta terrestre, ocorrendo no ar, no solo e na água. $\mathrm{O} \mathrm{Hg}$ é o único metal líquido a temperatura ambiente e pode ser encontrado nas formas químicas metálica ou elementar $\left(\mathrm{Hg}^{0}\right)$ inorgânica, principalmente na forma de sais mercuriais $\left(\mathrm{HgCl}_{2}, \mathrm{HgS}\right)$ e mercuroso $\left(\mathrm{Hg}_{2} \mathrm{Cl}_{2}\right)$, e orgânica ligado a radicais de carbono, como metil mercúrio e etil mercúrio. Diferentes espécies de mercúrio possuem diferentes propriedades químicas, biodisponibilidade e toxicidade (ASADUZZAMAN et al., 2015).

Cerca de $30 \%$ do $\mathrm{Hg}$ emitido para atmosfera é proveniente de atividades antrópicas, de processos industriais e, principalmente na obtenção do ouro, que é bastante frequente. No ambiente, o Hg também é incorporado de forma natural, devido à gaseificação da crosta terrestre, a emissões vulcânicas e à evaporação natural de corpos d'água.

Na Amazônia, a principal forma de emissão de $\mathrm{Hg}$ é advinda das atividades garimpeiras. Segundo Sá (2006), os primeiros registros de garimpagem de ouro na Amazônia são do século XVIII, tendo um aumento significativo na década de 70 do século passado devido ao valor recorde do preço do ouro no mercado internacional. A partir do final dos anos 70, as atividades de mineração contribuíram para elevadas emissões de mercúrio no ambiente (SANTOS et al., 2003). O Hg é utilizado no garimpo como forma de obter o ouro contido nos sedimentos das lavras garimpeiras. 0 trabalho desenvolvido nas lavras garimpeiras nos anos 70 era exclusivamente manual, localizando-se nas planícies de inundação dos cursos d'água, nos paleo-aluviões e, mais raramente, em aluviões ativos. O mercúrio apresenta-se como um elemento nocivo à saúde humana e pode causar doenças como epilepsia (CAITO e ASHNER, 2015), infarto do miocárdio (GENCHIN et al., 2017) e distúrbios respiratórios (HEINRICH et al. 2017), além de ser prejudicial ao meio ambiente, devido sua alta mobilidade e facilidade de se incorporar a outros elementos químicos. Atualmente a principal fonte de contaminação por mercúrio na Amazônia é a ingestão do contaminante por animais gerando ao longo do tempo a bioacumulação desse metal na cadeia alimen$\operatorname{tar}$ (ARRIFANO et al., 2018).

A agressão antrópica ao ambiente tem sido considerada de diversas formas mais agressivas ao longo da história do ser humano. O uso indiscriminado do mercúrio é mostrado como um dos exemplos mais representativos do que o homem pode causar danos aos ciclos naturais.

\section{OBJETIVOS}

Esta revisão tem como objetivo aprofundar o conhecimento sobre a ocorrência de mercúrio em solos e plantas, descrição dos métodos de determinação do metal; mercúrio no ecossistema amazônico, mobilidade do mercúrio no solo e sedimentos, assim como os impactos ambientais causados por esse metal.

\section{METODOLOGIA}

\subsection{Fontes de Mercúrio}

Entre os metais tóxicos, o mercúrio $(\mathrm{Hg})$ é um dos poluentes ambientais mais perigosos. A toxici- 
dade e mobilidade ambiental dos compostos de mercúrio estão intimamente relacionadas à sua forma química (DAGO et al., 2014). Este é um metal pesado não abundante na natureza; sua produção mundial está estimada em 10.000 t ano-1, sendo que Canadá, Rússia e Espanha são os principais produtores. Esse metal tem sido utilizado nas mais diversas áreas, como: produção de plantas clori-alcali; produção de monômero de cloreto de vinil (acetaldeído); baterias; lâmpadas fluorescentes e principalmente em mineração de ouro (KABATA-PENDIAS, 2011).

As maiores emissões de $\mathrm{Hg}$ global para atmosfera ocorrem devido à combustão de combustíveis fosseis (PACYNA, 2011). Devido a sua rápida industrialização, o continente asiático é um dos maiores emissores de $\mathrm{Hg}$ para atmosfera no mundo, destacando a China como o país que mais emite esse metal tóxico para o ar. Estudo realizado por Feng et al. (2005) na província de Guizhou, na China, relata que as emissões de $\mathrm{Hg}$ para o ecossistema chegaram a $55,5 \mathrm{t} \mathrm{ano}^{-1} \mathrm{com}$ a queima de carvão como combustível industrial.

A emissão de mercúrio para atmosfera é um grande problema a ser discutido, tendo em vista que é um dos principais motivos de mobilização desse metal para outros ecossistemas, pois o mercúrio é um elemento que dispersa rapidamente pelo ar. As emissões de $\mathrm{Hg}$ para a atmosfera podem ocorrer durante a produção e o consumo de bens industriais, eliminação de resíduos e re-emissão de superfícies aquáticas e terrestres. A produção de bens industriais é de longe a principal fonte de emissões atmosféricas de $\mathrm{Hg}$.

Segundo o estudo Global Mercury Assessment 2013 (ONU, 2013), as emissões de $\mathrm{Hg}$ na mineração dobraram desde 2005, chegando a 727 toneladas, correspondendo a 35\% do total mundial, enquanto a queima de carvão mineral é responsável por 475 t das emissões anuais. De 2005 a 2010 houve uma diminuição das emissões de $\mathrm{Hg}$ na Ásia, porém este ainda continua sendo o continente com maiores índices de emissão $\mathrm{Hg}$ no mundo (Fig. 1). Por outro lado, observa-se que na América do Sul a emissão foi de pouco mais de $200 \mathrm{t}$ de $\mathrm{Hg}$. Um dos motivos que levam ao aumento da emissão de $\mathrm{Hg}$ para atmosfera na América do Sul é o crescimento acentuado do desmatamento na Amazônia. De acordo com Pérez (2013), são liberadas aproximadamente 12 t de $\mathrm{Hg}$ com a queima da vegetação e exposição do solo superficial da floresta, e estima-se que a taxa de desmatamento na região entre 2000 e 2010 foi de 1,7 milhões de hectares.

Outro fator que explica o aumento de emissão de $\mathrm{Hg}$ para a atmosfera sul-americana é a utilização desse metal em atividades garimpeiras, principalmente na região norte do Brasil. Sabese que o $\mathrm{Hg}$ tem a capacidade de formar amálgamas com outros metais, sendo que isso leva à utilização de $\mathrm{Hg}$ em atividades garimpeiras para captura do ouro contido nos sedimentos.

Recentemente, a Global Mercury Assessment (ONU, 2018) publicou outro estudo sobre a emissão global de mercúrio para o ano de 2015 (Fig. 2). 0 estudo avaliou todas as regiões e descobriu que houve um aumento global de emissão se comparado a 2010. Em 2010, a emissão global de $\mathrm{Hg}$ foi de 1850 toneladas por ano; já em 2015 esse valor aumentou $35 \%$, chegando a 2500 toneladas por ano. Existem várias explicações para esse aumento como, por exemplo, o aumento de atividades econômicas industriais e o aumento de atividade econômica em algumas regiões, como a China. 


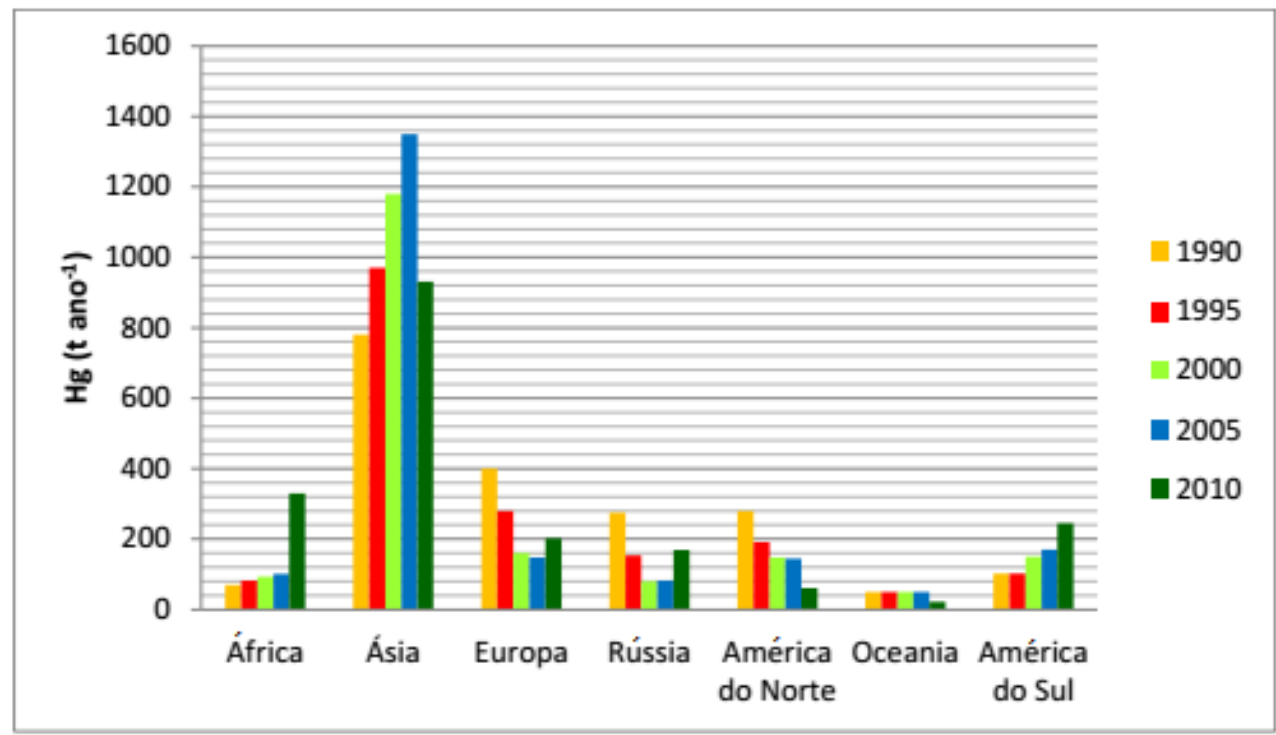

Figura 1 - Estimativas das emissões antropogênicas de mercúrio anuais de diferentes continentes /regiões, 1990-2010. Fonte: ONU, 2013.

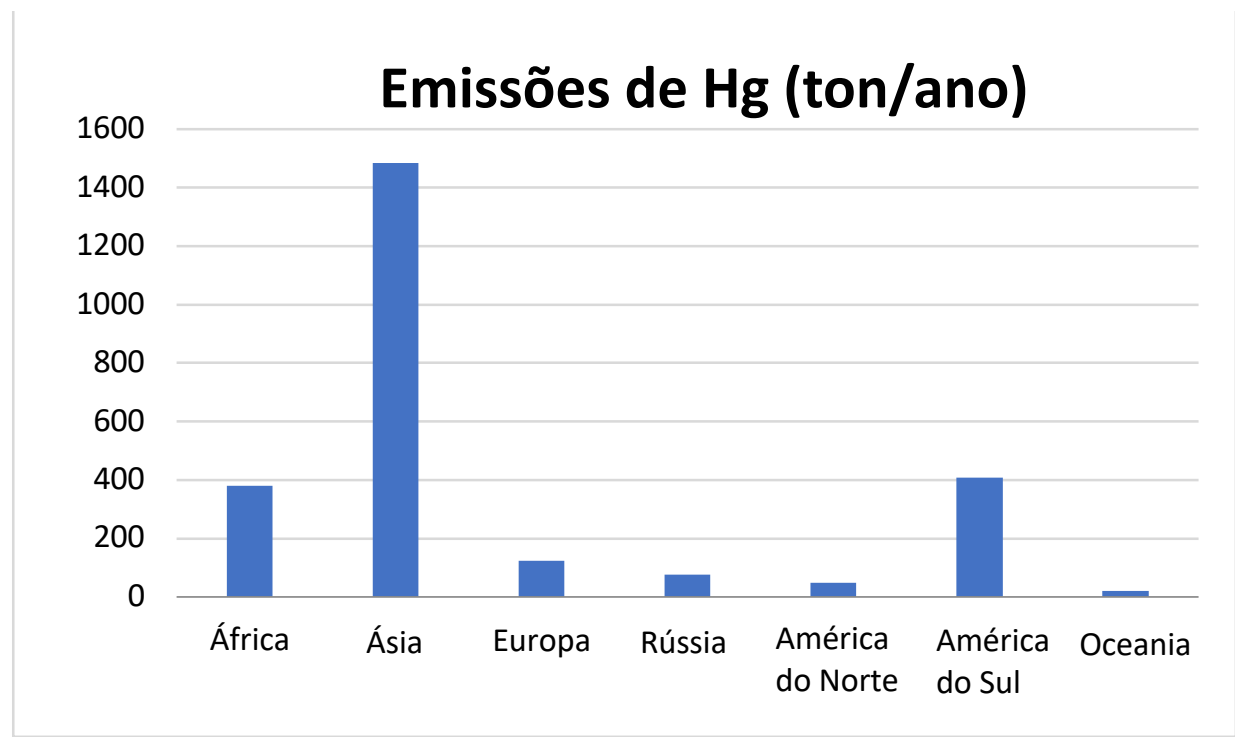

Figura 2 - Estimativas das emissões antropogênicas de mercúrio anuais de diferentes continentes/regiões, 2015 Fonte: ONU, 2018

\subsection{Mercúrio no ecossistema}

\subsubsection{Hg em solos}

A concentração de metais pesados em solos é dependente do material que deu origem àquele solo. Além da natureza do material de origem, outros fatores, como o teor e a composição da fração argila, conteúdo de matéria orgânica e condições físico-químicas dos solos, podem influenciar a concentração em metais pesados no solo. A concentração natural de $\mathrm{Hg}$ em solos em todo o mundo varia entre 0,58 e 1,8 $\mathrm{mg} \mathrm{kg}^{-1}$, e em média a concentração estimada é de $1,1 \mathrm{mg} \mathrm{kg}^{-1}$, sendo que os Cambissolos e Histossolos são as classes de solo que apresentam maiores teores de $\mathrm{Hg}$ em sua estrutura pedológica (KABATA-PENDIAS, 2011). O Hg 
não é muito móvel durante o intemperismo, apesar de formar várias espécies iônicas (Fig. 3), tendendo a ser retido fortemente no solo quando é adicionado na forma elementar ou como complexo iônico e catiônico (CARVALHO, 2011).

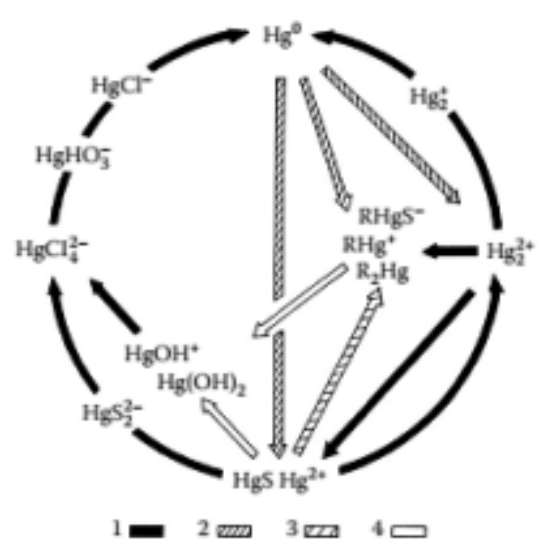

Figura 3 - Espécie iônica e transformações de compostos mercuriais em solos. (1) Redução

(2) Oxidação (3) Formação de compostos orgânicos

(4) Hidratação R: $\mathrm{CH} 3, \mathrm{CH} 3 \mathrm{CH} 2, \mathrm{C} 6 \mathrm{H} 5$. Fonte: Kabata-Pendias (2011).

Na sua forma mais tóxica, o metil mercúrioafeta a atividade microbiana do solo e destrói ecossistemas aquáticos. $O$ conhecimento da dinâmica de mercúrio nos solos possibilita a utilização de práticas preventivas e mitigadoras mais eficientes de forma a gerenciar a disponibilidade desse elemento, sua distribuição no ambiente e sua transferência para a cadeia alimentar. Por ser um metal que não sofre biodegradação, o $\mathrm{Hg}$ pode permanecer no ambiente por um longo período, e o tempo de permanência é o que determina o grau de contaminação no ecossistema.

Soares et al. (2015) analisaram 25 amostras de solo (PVA: Argissolo Vermelho-Amarelo distrófico típico; LVA: Latossolo Vermelho-Amarelo distrófico típico; LVd: Latossolo Vermelho distrófico típico; LVAd1: Latossolo Vermelho-Amarelo distrófico húmico; LVj: Latossolo Vermelho Perférrico húmico; NVef : Nitossolo Vermelho eutrófico típico; TCp: Luvissolo Crômico Pálico abrúptico; CXbe: Cambissolo Háplico Tb eutrófico latossólico; CXbd: Cambissolo Háplico Tb distrófico típico; FFcd1, FFcd2: Plintossolo Pétrico concrecionário distrófico; CXd: Cambissolo Háplico distrófico; RQQo: Neossolo Quartzarênico órtico latossólico; LVAd2: Latossolo VermeIho-Amarelo distrófico) para descobrir qual é o teor de $\mathrm{Hg}$ encontrado naturalmente no solo. Em seu estudos verificou-se que $48 \%$ do solo apresentam teor de $\mathrm{Hg}$ abaixo do valor de referência $\left(21 \mathrm{~g} \mathrm{~kg}^{-1}\right)$. Duas amostras demonstraram teores de $\mathrm{Hg}$ entre 50 e $100 \mu \mathrm{g} \mathrm{kg}^{-1}$ (LVj-B e PVA-A), sete amostras apresentaram teores de $\mathrm{Hg}$ entre $100 \mathrm{e}$ $150 \mu \mathrm{g} \mathrm{kg}{ }^{-1}$ (LVAd1-A, LVAd1-B, LVd-A, LVd-B, TCp-A, TCp-B e NVef-B), três entre 150 e $200 \mu \mathrm{g} \mathrm{kg}^{-1}$ (NVef-A, CXbd-B e CXbe-A) e apenas uma acima de $200 \mathrm{\mu g} \mathrm{kg}^{-1}$ (CXbe-B). Dentre as amostras com teores mais altos de $\mathrm{Hg}$ encontram-se os solos eutróficos avermelhados NVef e CXbe originários de basalto e calcário, respectivamente. De maneira geral, os teores de $\mathrm{Hg}$ encontrados nos solos estão acima das faixas encontradas na literatura para os teores do metal nos respectivos materiais litológicos de origem, o que pode significar que no processo pedogenético o $\mathrm{Hg}$ se concentra, diferentemente dos cátions mais móveis. É claro que não se pode excluir, mesmo para solos de mata nativa, a contribuição de $\mathrm{Hg}$ atmosférico, que pode ser transportado de fontes poluidoras distantes (GONZÁLEZ-FERNÁNDEZ et al., 2014). Estudos recentes também mostraram a importância dos processos de queima na remobilização do mercúrio no ecossistema amazônico (PEREZ et al., 2014).

Em estudos realizados por Różański et al. (2016) verificou-se que a mobilidade e a disponibilidade de mercúrio nos solos analisados foram muito baixas, com percentuais médios de 0,28 e 2,45\% do total do metal, respectivamente. Dependia principalmente da textura, da quantidade de matéria orgânica e do $\mathrm{pH}$ do solo. A porcentagem de mercúrio ligado à matéria orgânica variou de 
2,34 a 73,70\% do conteúdo total deste metal e foi correlacionada com a quantidade de argila e óxidos de Fe.

O processo de migração de $\mathrm{Hg}$ para o solo é bastante limitado, mesmo com quantidade baixa o conteúdo desse metal é construído lentamente na superfície do solo. Por outro lado, as perdas de $\mathrm{Hg}$ do solo por volatilização acentuam-se com o aumento da temperatura e da alcalinidade do solo.

As crescentes taxas de metilação nas águas e nos sedimentos são influenciadas pelo aumento da matéria orgânica, o que é atribuído ao efeito estimulante de nutrientes orgânicos sobre a atividade microbiana. No entanto, a influência do ácido húmico (um dos componentes da matéria orgânica) não é clara. Por um lado, o carbono orgânico pode aumentar a metilação por meio do estímulo da atividade dos microrganismos heterotróficos ou da metilação abiótica direta de $\mathrm{Hg}$ por substâncias húmicas e fúlvicas; por outro, as substâncias húmicas podem reduzir a disponibilidade de $\mathrm{Hg}^{+2}$ em ambientes tropicais (BISINOTI e JARDIM, 2004).

\subsubsection{Hg em plantas}

As plantas absorvem metais pesados da água e do solo. Analisando o mercúrio, o teor no solo é baixo, visto que esse metal está complexado com a matéria orgânica; assim, a concentração de mercúrio na parte aérea das plantas parece ser muito dependente da absorção foliar de $\mathrm{Hg}$ volatilizado do solo. As plantas podem apresentar diferentes mecanismos de tolerância em resposta ao excesso de metais pesados, incluindo a redução do transporte através da membrana, exclusão, formação de peptídeos ricos em grupos tiólicos (fitoquelatinas e metalotioneínas), quelação por ácidos orgânicos e aminoácidos, e compartimentalização de metal em estruturas subcelulares. A capacidade de absorção de mer- cúrio em vegetais permitiu estabelecer fatores que estimam tanto a transferência como a fitorremediação (VILLA et al., 2016).

Verifica-se uma inativação do elemento na membrana celular em plantas que crescem em ambientes com altas concentrações do metal. Esse processo acontece devido à formação de complexo entre os íons metálicos e os grupos sulfidrilas (-SH) produzidos pela planta. A propriedade química mais importante que explica grande parte dos danos biológicos causados pelo $\mathrm{Hg}$ é a elevada afinidade que esse metal possui pelo grupo sulfidrila das proteínas, causando inativação enzimática e desestruturação proteica (GIOVANELLA e BENTO, 2011).

As plantas são frequentemente usadas em solos de mineração para fitoextração de mercúrio; no entanto, estudos em agroecossistemas são mais escassos (Villa et al., 2016). Nas culturas de milho, o acúmulo de mercúrio foi evidenciado principalmente nas raízes, indicando que o risco de bioacumulação em humanos é baixo (PERALTAVIDEA et al., 2009).

Dados sobre fitotoxidade de $\mathrm{Hg}$ em plantas são bastante escassos, segundo mostra Mabhub et al. (2017). $\mathrm{O} \mathrm{Hg}$ inibe o crescimento das plantas (MONDAL et al., 2015; MAHBUB et al., 2017) e altera a morfologia e a fisiologia da planta (CLEMENS e MA , 2016), incluindo estresse oxidativo (TAMÁS et al., 2017; CHEN et al., 2017; TAMÁS e ZELINOVÁ, 2017) e prejuízos da fotossíntese líquida (MARRUGO-NEGRETE et al., 2016)

Segundo Rui et al. (2017) a tolerância de mercúrio em Cucurbitaceae é baixa em suas raízes, mas ocorre acúmulo de $\mathrm{Hg}$ em suas folhas. Esse fato é evidenciado nos estudos feitos por $\mathrm{Yu}, \mathrm{Li}$ e Luan (2018).

Entre as plantas aquáticas utilizadas para remediar $\mathrm{Hg}$ em águas contaminadas estão: Myriophyllum aquaticum, Myriophyllum spicatum, Hydrilla 
verticillata, Scirpus validus, Typha latifólia, Ceratophy llumdemersum e Lemna minor. Arenas, Marcó e Torres (2011) estudaram a eficiência de lemma minor como biorremediadora de $\mathrm{Hg}$ em águas com uma concentração do metal na água de 0,13 $\mathrm{mg} \mathrm{I}$ e constataram uma eficiência de remoção de $\mathrm{Hg}$ da Lemna minor de $30 \%$ em 22 dias.

Gil et al. (2013) estudou o comportamento do $\mathrm{Hg}$ em plantas de marrubio (Marrubium vulgare) no solo de uma antiga área metalúrgica, cujo $\mathrm{Hg}$ se encontrava na forma de Cinabrio (HgS). $\mathrm{O}$ autor utilizou dois sistemas de cultivo na área em hidroponia e no solo. Os resultados revelaram que as plantas crescidas hidroponicamente absorviam o metal através dos ápices das raízes, translocando-os para a parte aérea, enquanto as plantas cultivadas no solo apresentaram um comportamento exclusor, retendo o $\mathrm{Hg}$ na raizsem translocar para a parte aérea. Dessa forma, a planta consegue tolerar o $\mathrm{Hg}$ sem que este afete os tecidos da parte área e, consequentemente, o crescimento.

\subsubsection{Hg em humanos e peixes}

Uma das principais preocupações com os metais é a bioacumulação desses pela flora e fauna aquáticas, que pela cadeia alimentar acaba também atingindo o homem, ocasionando efeitos subletais e letais, devido a disfunções metabólicas (Souza et al., 2018). A contaminação por metais pesados se dá, principalmente, por meio da ingestão de água contaminada ou de peixes e outros animais que sofreram bioacumulação desses metais e da inalação de ar contaminado com fumaça industrial (ARAÚjO et al., 2017).

Em estudo realizado no mercado Ver-o-Peso no município de Belém, Amaro et al. (2014) analisaram três espécies de peixes em diferentes períodos sazonais: maio de 2011 (período menos chuvoso) e novembro de 2012 (período mais chuvoso) em 30 amostras de peixes, 10 de cada espécie. As espécies analisadas no estudo foram: Brachyplatystoma rousseauxii (dourada), Brachyplatystoma filamentosum (filhote), ambas de hábito alimentar carnívoro e Schizodon fasciatum (aracu), herbívoro. A média dos teores de $\mathrm{Hg}$ nas espécies não passaram de $0,5 \mathrm{mg} \mathrm{kg}^{-1}$ nos dois períodos estudados

Khoury et al. (2013) realizaram uma pesquisa semelhante, porém os resultados não mostraram concentrações médias superiores ao estabelecido pela OMS $\left(10 \mu \mathrm{g} \mathrm{g}^{-1}\right)$, apesar de alguns indivíduos estarem com concentrações acima desse valor, indicando contaminação. Nesse mesmo estudo, revelou que $33 \%$ da população analisada de São Luís do Tapajós e 24,4\% da população de Barreiras apresentou concentrações de $\mathrm{Hg}$ acima de $10 \mu \mathrm{g} \mathrm{g}^{-1}$, que é o valor máximo estabelecido pela OMS no organismo.

Chai et al. (2018) compararam concentrações em três espécies de peixes (Tor tambroides $1,31 \mathrm{mg} /$ $\mathrm{kg}$, Tor douronensis $0,70 \mathrm{mg} / \mathrm{kg}$ e Lobocheilos bo $0,41 \mathrm{mg} / \mathrm{kg}$ ) do rio Baleh de Sarawak, revelando altas concentrações de Hg na espécie Tor spp, evidenciando-se sua afinidade com mercúrio. A acumulação de $\mathrm{Hg}$ no organismo pode variar dependendo do tamanho, idade, habitat, alimentação, hábito e estágio de crescimento (RAIESHKUMAR e LI, 2018).

Milhomem Filho et al. (2016) avaliaram os níveis de exposição ao mercúrio em famílias de pescadores residentes em área ribeirinha do médio Tocantins. As espécies de hábitos piscívoro e zooplâncton apresentaram as maiores concentrações de mercúrio, sendo os valores médios do peixe cachorro $0,2775 \mu \mathrm{g} / \mathrm{g}$ e do mapará $0,1360 \mu \mathrm{g} / \mathrm{g}$. Dentre as 25 famílias avaliadas, a menor concentração média total/família foi $0,186 \pm 0,043 \mu \mathrm{g} / \mathrm{g}$, e a maior foi $5,477 \pm$ $2,896 \mu \mathrm{g} / \mathrm{g}$. Conclui-se que as famílias de Imperatriz possuem baixos níveis de exposição em vir- 
tude do consumo alimentar de peixes com baixos níveis de contaminação.

Para analisar a concentração de $\mathrm{Hg}$ no corpo humano é necessário fazer coleta de materiais que estão sujeitos à acumulação do metal, seja ela interna ou externa. $O$ fio de cabelo é um importante indicador de contaminação de $\mathrm{Hg}$ e tem sido muito utilizado por pesquisadores para fazer análise em populações ribeirinhas, assim como o sangue e a urina.

Marinho et al. (2014) analisaram amostras de cabelos de crianças em 3 comunidades na Amazônia (Comunidade São Luiz do Tapajós, Comunidade de Barreiras e Comunidade Maranhão). Os maiores níveis médios de $\mathrm{HgT}\left(11.41 \mu \mathrm{g} \cdot \mathrm{g}^{-1}\right)$ e MetilHg $\left(10,30 \mu \mathrm{g} \cdot \mathrm{g}^{-1}\right)$ em cabelos de crianças foram encontrados na comunidade de São Luiz do Tapajós. Esses valores são duas vezes a média de $\mathrm{HgT}\left(5.64 \mu \mathrm{g} \cdot \mathrm{g}^{-1}\right)$ e MetilHg $\left(5.20 \mu \mathrm{g} \cdot \mathrm{g}^{-1}\right)$ encontrado em Barreiras e quatro vezes maior que os resultados $\mathrm{THg}\left(2,27 \mu \mathrm{g} \cdot \mathrm{g}^{-1}\right)$ e $\mathrm{MetilHg}$ $\left(2,11 \mu \mathrm{g} \cdot \mathrm{g}^{-1}\right)$ na comunidade Maranhão.

A população ribeirinha é dependente do consumo de peixe para seu sustento. Os peixes são concentradores naturais de $\mathrm{Hg}$ e a sua quantidade nestes animais depende do alimento, bem como da idade e do tamanho. A contaminação humana por $\mathrm{Hg}$ depende não somente da quantidade de peixe consumido, mas também da espécie escolhida. $O$ consumo de peixe é um dos principais determinantes de exposição da população ao mercúrio como relatam Perez et al. (2019).

\subsection{Métodos de Determinação}

O desenvolvimento de técnicas para determinação do $\mathrm{Hg}$ é importante para estimar o seu real impacto no meio ambiente, principalmente para o sistema aquático, a vegetação e os seres humanos. $\mathrm{O}$ baixo nível de $\mathrm{Hg}$ em algumas amostras, a natureza volátil e a associação com outros elementos, exigem técnicas bastante sensíveis e precisas para sua determinação em diferentes matrizes.

O método colorimétrico é bastante simples, de baixo custo e rápido, porém sofre interferência de outros elementos, sendo necessárias várias etapas de separação. Este ainda é um método oficial opcional para a análise de água potável com teor de $\mathrm{Hg}$ superior a $2 \mu \mathrm{g} \cdot \mathrm{L}^{-1}$ (MARTINIANO et al., 2008).

A análise de ativação por nêutron consiste na irradiação de nêutrons na amostra produzindo cinco nucleotídeos, porém apenas o $\mathrm{Hg}$ com meia vida de 65 dias e o $\mathrm{Hg}$ com meia vida de 45 dias são determinados (BANSAL et al., 2011). Segundo esses autores, a análise por ativação com nêutrons é um método não destrutivo, específico e sensível para a determinação de mercúrio; no entanto, essa técnica é muito lenta e cara.

O método de absorção atômica convencional, utilizando chama, é bastante simples, baseandose na absorção da radiação pelos átomos de $\mathrm{Hg}$. Contudo, é pouco sensível e alguns interferentes podem comprometer o resultado analítico final, como o elemento cobalto. Nessa técnica, o Hg é reduzido a $\mathrm{Hg}^{0}$ pela adição de cloreto estanoso $\left(\mathrm{SnCl}_{2}\right)$ ou borohidreto de sódio $\left(\mathrm{NaBH}_{4}\right)$. É o método mais comum de análise e o recomendado oficialmente para a análise de águas e efluentes (BANSAL et al., 2011). A espectrofotometria de fluorescência atômica do vapor frio (CVAFS) é o mais utilizado, e consiste na detecção do sinal de fluorescência emitido pelo $\mathrm{Hg}$.

Costa Júnior et al. (2017) determinou $\mathrm{HgT}$ em dois municípios do Pará (Itaituba e Acará) utilizando a espectrofotometria de absorção atômica com amalgamação em lâmina de ouro; a máxima detectarão do método utilizado foi de 41,8 $\mu \mathrm{g} \cdot \mathrm{g}^{-1}$. As concentrações de $\mathrm{HgT}$ em Itaituba variaram de 0 a 41,8 $\mu \mathrm{g} / \mathrm{g}$, com média de 9,15 $\pm 8,17$ $\mu \mathrm{g} \cdot \mathrm{g}^{-1}$. Por outro lado, no Acará, a variação foi de 
0 a 2,34 $\mu \mathrm{g} \cdot \mathrm{g}^{-1} \mathrm{em}$ amostras de cabelo, com média de $0,67 \pm 0,54 \mu \mathrm{g} \cdot \mathrm{g}^{-1}$. Esse método também foi utilizado por outros autores (MILHOMEM FILHO et al., 2016; CORVELO et al., 2014; PINHEIRO et al., 2015).
Há uma variabilidade de técnicas analíticas (Tabela 1), e a escolha de cada uma é influenciada por diversos fatores, como o limite de detecção, tendo em vista que valores abaixo desse limite não são detectados pelo aparelho.

Tabela 1 - Técnicas analíticas mais frequentemente utilizadas para determinação de mercúrio total e/ou espécies de mercúrio e seus respectivos limites de detecção (LD) (Adaptado de MICARONI et al., 2000).

\begin{tabular}{|c|c|}
\hline Técnicas analíticas & Limite de Detecção \\
\hline Método Colorimétrico & $0,01-0,1 \mu \mathrm{g} \cdot \mathrm{g}^{-1}$ \\
\hline \multicolumn{2}{|c|}{ Espectrometria de Absorção Atômica } \\
\hline Forno de grafite (GFAAS) & $1 \mathrm{ng} \cdot \mathrm{g}^{-1}$ \\
\hline Vapor frio (CVAAS) & $0,01-1 \mathrm{ng} \cdot \mathrm{g}^{-1}$ \\
\hline \multicolumn{2}{|c|}{ Espectrometria de Fluorescência Atômica } \\
\hline Vapor frio (CVAFS) & $0,001-0,01 \mathrm{ng} \cdot \mathrm{g}^{-1}$ \\
\hline \multicolumn{2}{|c|}{ Análise por Ativação com Nêutrons } \\
\hline Instrumental (INAA) & $1-10 \mathrm{ng} \cdot \mathrm{g}^{-1}$ \\
\hline - Radioquímica (RNAA) & $0,01-1 \mathrm{ng} \cdot \mathrm{g}^{-1}$ \\
\hline \multicolumn{2}{|c|}{ Cromatografia Gasosa } \\
\hline Detector de Captura Eletrônica & $0,01-0,05$ ng.g ${ }^{-1}$ \\
\hline Detector de Emissão Atômica & $0,05 \mathrm{ng} \cdot \mathrm{g}^{-1}$ \\
\hline Espectrometria de Massa & $0,1 \mathrm{ng} \cdot \mathrm{g}^{-1}$ \\
\hline CVAAS / CVAFS & $0,01-0,05 \mathrm{ng} \cdot \mathrm{g}^{-1}$ \\
\hline \multicolumn{2}{|c|}{ Cromatografia Líquida de Alta Eficiência } \\
\hline Detector de Ultravioleta & $1 \mathrm{ng} \cdot \mathrm{mL}^{-1}$ \\
\hline CVAAS & $0,5 \mathrm{ng} \cdot \mathrm{mL}^{-1}$ \\
\hline CVAFS & $0,08 \mathrm{ng} \cdot \mathrm{mL}^{-1}$ \\
\hline Eletroquímico & $0,1-1 \mathrm{ng} \cdot \mathrm{mL}^{-1}$ \\
\hline \multicolumn{2}{|c|}{ Plasma Acoplado Indutivamente } \\
\hline Espectrometria de Massa (ICP MS) & $0,01 \mathrm{ng} \cdot \mathrm{mL}^{-1}$ \\
\hline Espectrometria de Emissão Atômica (ICP AES) & $2 \mathrm{ng} \cdot \mathrm{mL}^{-1}$ \\
\hline Espectrometria Foto-Acústica & $0,05 \mathrm{ng} \cdot \mathrm{g}^{-1}$ \\
\hline Fluorescência de Raio-X & $0,005-1 \mu \mathrm{g} \cdot \mathrm{g}^{-1}$ \\
\hline Métodos Eletroquímicos & $0,1-1 \mu \mathrm{g} \cdot \mathrm{g}^{-1}$ \\
\hline Analisador de Filme de Ouro & $0,05 \mu \mathrm{g} \cdot \mathrm{g}^{-1}$ \\
\hline
\end{tabular}

Em relação ao $\mathrm{Hg}$ e MetilHg, na literatura são relatados vários procedimentos e técnicas analíticas para a sua determinação; contudo, o desenvolvimento desses métodos para quantificação de MetilHg em amostras biológicas não é tão simples, devido aos problemas relacionados à extração do analito da amostra e ao método de quantificação final empregado.

Martiniano et al. (2008) otimizaram um novo método espectrofotométrico simples, sensível e com boa seletividade, ao adicionar como reagente o 2-mercapto-5- metilbenzilimidazol $(\mathrm{MMBI})$ em um meio aquoso alcalino. $\mathrm{O}$ método desenvolvido permitiu a determinação de mercúrio na faixa de $2 \times 10^{-6}$ a $4 \times 10^{-5} \mathrm{~mol} \mathrm{~L}^{-1} \mathrm{com}$ boa precisão e exatidão, e o limite de detecção para $\mathrm{Hg}$ foi de $9,9 \times 10^{-7} \mathrm{~mol} \mathrm{~L}^{-1}$. $\mathrm{O}$ método foi aplicado com sucesso a amostras de peixe e os resultados foram avaliados com o clássico método de espectrometria de absorção atômica (EAA). Os desvios padrão relativos para as amostras analisadas foram de 7,2 e 33\% ( $n=5)$, enquanto os erros foram de 1,63 e 11,6. O método mostrou-se sensível, seletivo e foi aplicado para a determinação de $\mathrm{Hg}$ em amostras de peixe com resultados satisfatórios. 


\section{CONSIDERAÇÕES FINAIS}

É necessária a devida atenção da comunidade científica de todo o mundo sobre a contaminação ambiental por mercúrio, principalmente na região amazônica. Desde a década de 70 do século passado, a Amazônia continua como cenário de atividade garimpeira, causando degradação dos solos e contaminação ambiental, expondo à contaminação humana de populações vizinhas às fontes geradoras. As altas concentrações de mercúrio encontradas nos ecossistemas amazônicos não são atribuídas somente à atividade de mineração, mas também à presença de solos com concentrações relativamente elevadas de origem natural, ao transporte atmosférico e à deposição de mercúrio de origem antrópica devido ao desmatamento e às queimadas da vegetação.

A extração artesanal de ouro, indústria de cloro-soda, queimadas, queima de combustíveis fósseis, setor farmacêutico e de saúde, setor eletroeletrônico e odontologia são algumas das principais fontes de emissão de mercúrio para a atmosfera. 0 mercúrio pode ser encontrado no ar, na água e no solo. No ambiente terrestre, o $\mathrm{Hg}$ causa sérios danos às plantas. A mobilidade no solo de $\mathrm{Hg}$ é controlada pelas as espécies do elemento e pelos atributos do solo, $\mathrm{pH}$, matéria orgânica e minerais argila.

Ao se acumular nas raízes, afeta os processos de assimilação de nutriente presente no solo e nas folhas produzem graves danos nos cloroplastos e nas mitocôndrias, o que altera os processos fotossintéticos e respiratórios. No ecossistema aquático, sua forma mais tóxica é o metil mercúrio, que surge a partir da metilação do mercúrio elementar realizado por bactérias. Ao sofrer metilação no sistema aquático, o metil mercúrio pode se acumular nos tecidos das plantas aquáticas e principalmente nos peixes. Devido a sua bioacumulação, o metil mercúrio permanece na cadeia alimentar por muito mais tempo. Esse processo é conhecido como biomagnificação trófica, e o principal prejudicado é o homem, por estar no topo da cadeia alimentar. As populações ribeirinhas são as mais prejudicadas, pelo fato de serem dependentes dos peixes e de produtos vegetais locais para seu sustento.

Em função disso, são necessárias ações governamentais no sentido de remediar e reduzir a contaminação ambiental, ao mesmo tempo em que as populações expostas ao $\mathrm{Hg}$ devem ser orientadas e conscientizadas sobre os riscos a que estão expostas. Nesse sentido, vários países estão adotando políticas de gerenciamento e monitoramento de sua utilização, eliminando o mercúrio de alguns produtos ou substituindo por outras substâncias.

\section{CONTRIBUIÇÃO DOS AUTORES}

Todos os autores contribuíram de forma igualitária.

\section{REFERÊNCIAS}

AMARO, C. S. O; JUNIOR, D. R.; SILVA, M. C. F.; LIMA, A. A. S.; SANTOS, G. F. S.; et al. Concentração de mercúrio total $(\mathrm{Hg}-\mathrm{T})$ em peixes comercializados em diferentes períodos sazonais. Revista Pan-Amazônica de Saúde. v. 5, n. 1,p. 53-60, 2014. Disponível em: <http://scielo.iec.gov.br/scielo.php?script=sci_ arttext\&pid=S2176-62232014000100006>. http://dx.doi. org/10.5123/S2176-62232014000100006.

ARAÚJO, A. D.; FREITAS, M. O.; MOURA, L. C.; BAGGIO FILHO, H.; CAMBRAIA, R. P. Avaliação geoquímica ambiental do garimpo Areinha: estudo da concentração e distribuição de metais pesados nos sedimentos e os danos à saúde humana. Hygea: Revista Brasileira de Geografia Médica e da Saúde. V. 13, n. 26, p. 98113, 2017. Disponível em: <http://www.seer.ufu.br/index.php/ hygeia/article/view/39728>. https://doi.org/10.14393/132608.

ARENAS, A. D.; MARCÓ, L-M.; TORRES, G. Evaluation of the plant Lemna minor for the bioremediation of water contaminated with mercury. Avances En Ciencias e Ingenierĺa. V. 3, n. 2, p.111, 2011. Disponível em: <https://www.redalyc.org/articulo. oa?id=323627683001>.

ARRIFANO, G.P.F.; MARTÍN-DOIMEADIOS, R. C. R., JIMÉNEZ-MORENO, M.; RAMÍREZ-MATEOS, V.; DA SILVA, N. F. S.; et al. Large-scale projects in the amazon and human exposure to mercury: The case-study of the Tucuruí Dam. Ecotoxicology and Environmental Safety. v. 147, 
p. 299-305. jan. 2018. Disponível em: <https://www.sciencedirect. com/science/article/pii/S0147651317305444?via\%3Dihub>. https://doi.org/10.1016/j.ecoenv.2017.08.048.

ASADUZZAMAN, K.; KHANDAKER, M. U.; AMIN, Y. M.; ZAINUDDIN, Z.; FAROOK, M. S. Measurement of radioactivity and heavy metal levels in edible vegetables and their impact on Kuala Selangor communities of Peninsular Malaysia. Radiation Protection Dosimetry 167,165-170,2015. Disponível em:<https://academic. oup.com/rpd/article-abstract/167/1-3/165/2375253>. https:// doi.org/10.1093/rpd/ncv237.

BANSAL, N.; VAUGHAN, J.; BOULLEMANT, A.; LEONG, T. The Determination of Trace Mercury in Environmental Samples: $A$ Review. School Of Chemical Engineering, Queensland, v. 2, n. 21, p.16-22, 2011. Disponível em: <https://pdfs.semanticscholar. org/41ae/97482deabf32542ddcd9dc142e845b934c36.pdf>.

BISINOTI, M. C.; JARDIM, W. F. O comportamento do metilmercúrio (metilHg) no ambiente. Química Nova. V. 27, n. 4, p. 593600, 2004. Disponível em: <http://quimicanova.sbq.org.br/ imagebank/pdf/Vol27No4_593_13-RV03094.pdf>.

CAITO, S.; ASCHNER, M. Chapter 11 - Neurotoxicity of metals. Occupational Neurology, 169-189, 2015. Disponível em: <https://sci-hub.tw/10.1016/b978-0-444-62627-1.00011-1>. https://doi.org/10.1016/B978-0-444-62627-1.00011-1.

CARRASCO-GIL, S.; SIEBNER, H.; LEDUC, D. L.; WEBB, S. M.; MILLÁN, R.; et al. Mercury Localization and Speciation in Plants Grown Hydroponically or in a Natural Environment. Environmental Science \& Technology. V. 47, n. 7, p.3082-3090, 2013. Disponível em: <https://pubs-acs-org.ez3.periodicos.capes.gov.br/doi/ ipdf/10.1021/es303310t>. http://dx.doi.org/10.1021/es303310t.

CHAI, H. P.; NYANTI, L.; GRINANG, J.; LING, T. Y.; SIM, S. F. Assessment of heavy metals in water, fish and sediments of the Baleh River, Sarawak, Malaysia. Borneo Journal of Resource Science and Technology. V. 8, n. 1, p. 30-40, 2018. Disponível em: <http:// publisher.unimas.my/ojs/index.php/BJRST/article/view/822>. https://doi.org/10.33736/bjrst.822.2018.

CHEN, Z.; CHEN, M.; JIANG, M. Hydrogen sulfide alleviates mercury toxicity by sequestering it in roots or regulating reactive oxygen species productions in rice seedlings. Plant Physiology and Biochemistry. V. 111, p. 179-192, 2017. Disponível em: <https:// www-sciencedirect.ez3.periodicos.capes.gov.br/science/ article/pii/S0981942816304582>. https://doi.org/10.1016/j. plaphy.2016.11.027.

CLEMENS, S.; MA, J. F. Toxic heavy metal and metalloid accumulation in crop plants and foods. Annual Review of Plant Biology. V. 67, p. 489-512, 2016. Disponível em: <https://wwwannualreviews-org.ez3.periodicos.capes.gov.br/doi/10.1146/ annurev-arplant-043015-112301>. https://doi.org/10.1146/ annurev-arplant-043015-112301.

CORVELO, T. C. O.; OLIVEIRA, E. A. F.; PARIJÓS, A. M.; OLIVEIRA, C. S. B.; LOIOLA, R. S. P.; et al. Monitoring mercury exposure in reproductive aged women inhabiting the Tapajós river basin, Amazon. Bulletin of Environmental Contamination and Toxicology. V. 93(1), p. 42-46, 2014. Disponível em: <https://link-springer-com.ez3.periodicos. capes.gov.br/article/10.1007/s00128-014-1279-5>. https://doi. org/10.1007/s00128-014-1279-5.

DAGO, A.; GONZÁLEZ, I.; ARiñO, C.; MARTíNEZ-CORONADO, A.; HIGUERAS, P.; et al. Evaluation of Mercury stress in plants from the Almadén mining district by analysis of phytochelatins and their $\mathrm{Hg}$ complexes. Environmental Science \& Technology. V. 48, n. 11, p. 6256-6263, 2014. Disponível em: <https://pubs-acs-org.ez3. periodicos.capes.gov.br/doi/pdf/10.1021/es405619y>. https:// doi.org/10.1021/es405619y.

FENG, X.; WANG, S.; QIU, G.; HOU, Y.; TANG, S. Total gaseous mercury emissions from soil in Guiyang, Guizhou, China, Journal Geophysics Research, v. 110, 2005. Disponível em: <http://www. paper.edu.cn/scholar/showpdf/NUj2MN2IMTTOExeQh>. https:// doi.org/10.1029/2004JD005643.

GENCHI, G.; SINICROPI, M. S.; CAROCCI, A.; LAURIA, G.; CATALANO, A. Mercury Exposure and Heart Diseases. International Journal of Environmental Research and Public Health, v. 14(1): 74, 2017. Disponível em: <https://www.ncbi.nlm.nih.gov/pmc/articles/ PMC5295325/>. https://doi.org/10.3390/ijerph14010074.

GIOVANELLA, P.; BENTO, F.; CABRAL, L.; GIANELLO, C.; CAMARGO, F. A. O. Isolamento e seleção de microorganismos resistentes e capazes de volatilizar mercúrio. Química Nova. V. 34 (2), p. 232- 236, 2011. Disponível em: <http://www.scielo.br/scielo. php?script=sci_arttext\&pid=S0100-40422011000200012>. http://dx.doi.org/10.1590/S0100-40422011000200012.

GONZÁLEZ-FERNÁNDEZ, B.; MENÉNDEZ-CASARES, E.; MELÉNDEZ-ASENSIO, M.; FERNÁNDEZ-MENÉNDEZ, S. Sources of Mercury in groundwater and. soils of West Gijón (Astúrias, NW Spain). Science of the Total Environment. V. 481, p. 217-231, 2014. Disponível em: <https://www-sciencedirect.ez3.periodicos. capes.gov.br/science/article/pii/S004896971400196X>. https:// doi.org/10.1016/j.scitotenv.2014.02.034.

HEINRICH, J.; GUO, F.; TREPKA, M. J. Brief report: low-level mercury exposure and risk of asthma in school-age children. Epidemiology v. 28(1), p.116-118, 2017. Disponível em: <https://oceovid.ez3. periodicos.capes.gov.br/article/00001648-201701000-00018/ HTML>. https://doi.org/10.1097/EDE.0000000000000576.

KABATA-PENDIAS, A. Trace Elements in Soils and Plants, 4th Ed. Boca Raton: CRC, 2011.505 p.

KHOURY, E. D. T.; SOUZA, G. S.; SILVEIRA, L. C. L.; COSTA, C. A.; ARAÚjO, A. A.; et al. Manifestações neurológicas em ribeirinhos de áreas expostas ao mercúrio na Amazônia brasileira. Caderno de Saúde Pública, Rio de Janeiro, v. 11, n. 29, p.2307-2318, 2013. Disponível em: <http://www.scielo.br/pdf/csp/v29n11/17.pdf>. http://dx.doi.org/10.1590/0102-311x00158012.

MAHBUB, K. R.; KADER, M.; KRISHNAN, K.; LABBATE, M.; NAIDU, R.; MEGHARAJ, M. Toxicity of Inorganic Mercury to Native Australian 
Grass Grown in Three Different Soils. Bulletin of Environmental Contamination and Toxicology. V. 98: 850-855, 2017: Disponível em: <https://link-springer-com.ez3.periodicos.capes.gov.br/ article/10.1007/s00128-017-2096-4>. https://doi.org/10.1007/ s00128-017-2096-4.

MARINHO, J. S.; LIMA, M. O.; SANTOS, E. C.; JESUS, I. M.; PINHEIRO, M. C. N.; et al. Mercury Speciation in Hair of Children in Three Communities oftheAmazon, Brazil.Biomed Research International. 2014. Disponível em: <https://www.hindawi.com/journals/ bmri/2014/945963/>. http://dx.doi.org/10.1155/2014/945963.

MARTINIANO, L. C.; BEZERRA, C.W.B.; MARQUES, E.P.; SOUSA, A.G.; FERNANDES, R.N. Novo método espectrofotométrico para determinação de $\mathrm{Hg}$ (II) em amostras de peixe. Ciência e Tecnologia Alimentar. V. 28(2), p. 373-379, 2008. Disponível em: http://www.scielo.br/scielo.php?frbrVersion=3\&script=sci_ arttext\&pid=S0101-20612008000200016\&lng=en\&tlng=en http://dx.doi.org/10.1590/S0101-20612008000200016.

MICARONI, R.C.C.M.; BUENO, M.I.M.S.; JARDIM, W.F. Compostos de Mercúrio: revisão de métodos de determinação, tratamento e descarte.Química Nova,v.23,n.4, p.487-495,2000.Disponívelem: http://www.scielo.br/scielo.php?script=sci_arttext\&pid=S010040422000000400011\&lng=en\&nrm=iso\&tlng=pt>. http:// dx.doi.org/10.1590/S0100-40422000000400011.

MILHOMEM FILHO, E. O.; OLIVEIRA, C. S. B.; SILVEIRA, L. C. L.; CRUZ, T. M.; SOUZA, G. S.; et al. A ingestão de pescado e as concentrações de mercúrio em famílias de pescadores de Imperatriz (MA). Revista Brasileira de Epidemiologia. V. 19, n. 1, p. 14-25, 2016. Disponível em: <http://www.scielo.br/pdf/rbepid/ v19n1/1980-5497-rbepid-19-01-00014.pdf>. http://dx.doi. org/10.1590/1980-5497201600010002.

MARRUGO-NEGRETE, J.; DURANGO-HERNÁNDEZ, J.; PINEDOHERNÁNDEZ, J.; ENAMORADO-MONTES, G.; DÍEZ, S. Mercury uptake and effects on growth in Jatropha curcas. Journal of Environmental Sciences. V. 48, p. 120-125, 2016. Disponível em: <https://wwwsciencedirect.ez3.periodicos.capes.gov.br/science/article/pii/ S1001074216301279>. https://doi.org/10.1016/j.jes.2015.10.036.

MONDAL, N. K.; DAS, C.; DATTA, J. K. Effect of mercury on seedling growth, nodulation and ultrastructural deformation of Vigna radiata $(\mathrm{L})$ Wilczek. Environmental Monitoring and Assessment. V. 187(5), p. 1-14, 2015. Disponível em: <https://link-springercom.ez3.periodicos.capes.gov.br/article/10.1007/s10661-0154484-8>. https://doi.org/10.1007/s10661-015-4484-8.

PINHEIRO, M. C. N.; FARRIPAS, S. S. M.; OIKAWA, T.; COSTA, C. A.; AMORAS, W. W.; et al. Temporal Evolution of exposure to mercury in riverside communities in the Tapajós Basin, from 1994 to 2010. Bulletin of Environmental Contamination and Toxicology. V. 89(1), p. 119-124, 2012. Disponível em: <https://link-springercom.ez3.periodicos.capes.gov.br/article/10.1007/s00128-0120652-5>. https://doi.org/10.1007/s00128-012-0652-5.
ORGANIZAÇÃO DAS NAÇÕES UNIDAS. Global Mercury Assessment 2018. Programa de Meio Ambiente, Produtos Químicos e Agência de Saúde, 2018. Disponível em: <https:// wedocs.unep.org/bitstream/handle/20.500.11822/27579/ GMA2018.pdf? sequence $=1$ \&isAllowed $=y>$.

ORGANIZAÇÃO DAS NAÇÕES UNIDAS. Global Mercury Assessment 2013. Programa de Meio Ambiente, Produtos Químicos e Agência de Saúde, 2013. Disponível em: <https:// wedocs.unep.org/bitstream/handle/20.500.11822/27579/ GMA2013.pdf?sequence $=1$ \&isAllowed $=y$ >

PERALTA-VIDEA,J.R.;LOPEZ,M.L.;NARAYAN,M.;SAUPE, G.;GARDEATORRESDEY, J. The biochemistry of environmental heavy metal uptake by plants: Implications for the food chain. International Journal of Biochemistry \& Cell Biology. V. 41, n. 8-9, p. 1665-1677, 2009. Disponível em: <https://www-sciencedirect.ez3.periodicos. capes.gov.br/science/article/pii/S1357272509001009>. https:// doi.org/10.1016/j.biocel.2009.03.005.

PEREZ, J. M.; FOSTIER, A. H.; CARVALHO JR, J. A.; WINDMÖLLER, C. C.; SANTOS, J. C.; CARPI, A. Soil and biomass mercury emissions during a prescribed fire in the Amazonian rain forest. Atmospheric Environment. V. 96, p. 415-422, 2014. Disponível em: <https:// www-sciencedirect.ez3.periodicos.capes.gov.br/science/ article/pii/S1352231014004786>. https://doi.org/10.1016/j. atmosenv.2014.06.032.

PÉREZ, R.; SUELVES, T.; MOLINA, Y.; CORPAS-BURGOS, F.; YUSÀ, V. Biomonitoring of mercury in hair of children living in the Valencian Region (Spain). Exposure and risk assessment. Chemosphere. V. 217, 558-566, 2019. Disponível em: <https:// www-sciencedirect.ez3.periodicos.capes.gov.br/science/ article/pii/S1352231014004786>. https://doi.org/10.1016/j. chemosphere.2018.11.017.

RAIESHKUMAR, S.; LI, X. Bioaccumulation of heavy metals in fish species from the Meiliang Bay, Taihu Lake, China. Toxicology Report. V. 5, p. 288-295, 2018. Disponível em: <https:// www-sciencedirect.ez3.periodicos.capes.gov.br/science/ article/pii/S2214750018300477>. https://doi.org/10.1016/j. toxrep.2018.01.007.

RÓŻAŃSKI, S. L.; CASTEJÓN, J. M. P.; FERNÁNDEZ, G. G. Bioavailability and mobility of mercury in selected soil profiles. Environmental Earth Sciences. V. 75, 2016. Disponível em: <https://link.springer.com/article/10.1007/s12665-016-58633>. https://doi.org/10.1007/s12665-016-5863-3.

RUI, L; HAN, W.; DING, J.; FU, W.; GAN, L.; et al. Mercury pollution in vegetables, grains and soils from areas surrounding coalfered power plants. Scientifc Reports. V. 7, 2017. Disponível em: <https://www.nature.com/articles/srep46545>. https://doi. org/10.1038/srep46545.

SOARES, L. C.; LINHARES, L. A.; EGREJA FILHO, F. B.; WINDMOLLER, C. C.; YOSHIDA, M. I. Mercúrio em Solos da Região Sudeste do Brasil sem Influência Antropogênica e sua Correlação com as 
Características Químicas e Físicas. Revista Brasileira de Ciência do Solo. V. 39, n. 3, p.903-914, 2015. Disponível em: <https:// www.sbcs.org.br/wp-content/uploads/2015/07/V39N3a27. http://dx.doi.org/10.1590/01000683rbcs20140411.

SOUZA, A. K.R.; MORASSUTI, C. Y.; DE DEUS, W. B. Poluição do ambiente por metais pesados e utilização de vegetais como bioindicadores. Acta Biomedica Brasiliensia. V. 9, n. 3, p. 95-106, 2018. Disponível em: <http://actabiomedica.com.br/index.php/ acta/article/view/300>. http://dx.doi.org/10.18571/acbm.189.

SÁ, A.L. et al, Exposição humana ao mercúrio na região oeste do estado do Pará. Revista Paraense de Medicina, 20 (1), 2006.

SANTOS, E.C.O. et al. Exposição ao mercúrio e ao arsênio em Estados da Amazônia: síntese dos estudos do Instituto Evandro Chagas/FUNASA. Revista Brasileira de Epidemiologia, 6 (2), 171-185, 2003.

TAMÁS, L.; MISTRÍK, L.; ZELINOVÁ, V. Heavy metal-induced reactive oxygen species and cell death in barley root tip. Environmental and Experimental Botany. V. 140, p. 34-40, 2017. Disponível em: $\quad$ https://www-sciencedirect.ez3.periodicos.capes.gov. br/science/article/pii/S0098847217301302>. https://doi. org/10.1016/j.envexpbot.2017.05.016.

TAMÁS, L.; ZELINOVÁ, V. Mitochondrial complex II-derived superoxide is the primary source of mercury toxicity in barley root tip. Journal of Plant Physiology. V. 209, p. 68-75, 2017. Disponível em: <https://www-sciencedirect.ez3.periodicos. capes.gov.br/science/article/pii/S0176161716302668>. https:// doi.org/10.1016/j.jplph.2016.10.014.

YU, H.; LI, J.; LUAN, Y. Meta-analysis of soil mercury accumulation by vegetables. Scientific Reports. V. 8, n. 1, p.1-10, 2018. Disponível em: <https://www.nature.com/articles/s41598-01819519-3>. http://dx.doi.org/10.1038/s41598-018-19519-3.

WHO. Concise International Chemical Assessment Document 50. Elemental Mercury and Inorganic Mercury Compounds: Human Health Aspects. Geneva, 2003. 